\title{
PRESENTACION
}

\section{Antonio Martín-Artiles}

Centre d'Estudis Sociològics sobre la Vida Quotidiana i el Treball (QUIT). Institut d'Estudis del Treball (IET) Universitat Autònoma de Barcelona, 08193- Bellaterra, Spain

antonio.martin@uab.cat

REFERENCIA NORMALIZADA

Martín-Artiles, Antonio (2017): “Presentación”. Anuario IET de Trabajo y Relaciones Laborales, Vol. 4, iii-v. http://dx.doi.org/10.5565/rev/aiet.49 


\section{PRESENTACIÓN}

El objetivo del Anuario es analizar los efectos de la Gran Recesión en el aumento de las desigualdades sociales y laborales. Desde el inicio de la Gran Recesión —en el año 2007/08 - se han venido impulsado políticas de austeridad que han implicado un aumento de las desigualdades laborales, así como un aumento de la brecha salarial entre hombres y mujeres. Esta política de austeridad está asociada en los países del Sur de Europa a la devaluación salarial, cuya finalidad es pretender mejorar la capacidad competitiva de la economía. Además de ser de paso un instrumento de recomposición de la disciplina laboral.

El alto volumen de desempleo ha jugado un papel importante en los inicios de la Gran Recesión, lo que ha afectado primordialmente a los hombres, en la medida que éstos estaban en mayor proporción empleados en sectores intensivos en mano de obra, como en la construcción, la hostelería, entre otros. Pero posteriormente los efectos de la Gran Recesión se han hecho sentir en los sectores de servicios, lo que finalmente ha acabado por afectar también al empleo femenino.

Las desigualdades van mucho más allá de la brecha salarial. Las desigualdades han afectado a la calidad del empleo, así como al empleo a tiempo parcial que ha venido creciendo. Igualmente, la desigualdad tiene un componente generacional: los jóvenes tienen hoy escasas expectativas de encontrar empleos de calidad, sus trayectorias laborales son inciertas. La incertidumbre no solo afecta a los jóvenes, sino también a los trabajadores mayores de 45 años, un colectivo que tiene una difícil empleabilidad. En resumen, incertidumbre y desigualdad son hoy los resultados heredados de la Gran Recesión y de la política de austeridad. Incertidumbre y desigualdad no son nada halagüeñas para los próximos años, lo que plantea retos políticos y sindicales de enorme envergadura.

Este anuario se estructura en cuatro secciones.

En la primera sección, titulada (I) Evolución y características del mercado de trabajo, trataremos los efectos de la recesión sobre las desigualdades, así como sus efectos en la transición de los jóvenes en el mercado de trabajo. El artículo de Martí López y de Joan Miquel compara los casos de España y el Reino Unido, donde la política de austeridad ha tenido efectos notables sobre las desigualdades y la incertidumbre. El siguiente artículo trata del aumento de las desigualdades en los casos de España y Argentina de la mano de Pedro López-Roldán y Sandra Fachelli. La finalidad de este artículo es construir un modelo de segmentación general y estructural para analizar las desigualdades sociales en el mercado de trabajo y plantear la comparación de una tipología de posiciones o segmentos de empleo entre los dos países mencionados.

En la segunda sección, titulada (II) Relaciones laborales y negociación colectiva, Francesc Pérez Amorós nos ofrece una perspectiva de las desigualdades desde el derecho del trabajo, que reflexiona sobre la devaluación salarial derivada de la reforma laboral de 2012 (Ley $3 / 2012$, de 6 de julio, de medidas urgentes para la reforma del mercado del trabajo).

En la tercera sección, titulada (III) Políticas de empleo, tenemos otros dos artículos. El artículo de Fausto Miguélez presenta los resultados de un estudio que evalúa las políticas de empleo en España. En el año 2015, cuando se realiza este estudio; era un momento en el que resultaba adecuado recabar la opinión de expertos y técnicos cualificados de la Administración sobre las políticas que el gobierno ponía en funcionamiento para potenciar la creación de empleo y salir de la crisis, pero también para la opinión de los expertos sobre posibles alternativas. Igualmente, en esta sección sobre el empleo escribe Josep Banyuls y Albert Recio, quienes analizan el contexto de la crisis actual y el crecimiento de los trabajadores y trabajadoras pobres. Esta es una nueva realidad: las tasas de pobreza en España se encuentran entre las más altas de Europa. Habitualmente la pobreza se relacionada con el desempleo y la jubilación. Pero desde 2007 las características de las personas afectadas han cambiado radicalmente. Colectivos que tradicionalmente se consideraban "protegidos" — personas ocupadas, con nivel educativo alto...- ahora ya no lo están.

En la cuarta Sección (IV) Negociación colectiva, incluimos un artículo de Oscar Molina y Alejandro Godino sobre negociación colectiva y cláusulas de productividad, aspecto cada vez más relevante en el desarrollo de la negociación colectiva, este artículo es el resultado de un estudio comparado con otros países europeos. En la misma línea, Ramón Alós, Pére Jódar y Pere Beneyto analizan los efectos de la reforma laboral de 2012 sobre la negociación colectiva y sobre el sindicalismo. La descentralización ha perseguido adecuar el contenido de la negociación colectiva a la situación específica de las empresas, a la vez que ha venido debilitando al sindicalismo general.

En la quinta sección, titulada (V) Vulnerabilidad y mercado de trabajo, Vicent Borras y Sara MorenoColom presentan los resultados de un estudio sobre la empleabilidad de los jóvenes. En concreto, esta investigación se pregunta hasta qué punto las consecuencias de la crisis de la ocupación (con altas tasas de paro, inactividad y precariedad) están 
sustrayendo peso al trabajo productivo en el proyecto vital de los jóvenes en transición a la vida adulta. El artículo profundiza en la idea de que el escaso empleo y sus malas condiciones laborales contribuyen a la transformación del valor del trabajo en las generaciones de jóvenes. Otro estudio sobre la vulnerabilidad es el realizado por Núria Sánchez Mira sobre la brecha salarial entre hombres y mujeres, que se ha venido agrandando durante el periodo de crisis económica. En esta misma sección, otro artículo de Antonio MartínArtiles, Andreu Lope, Benjamí Moles y Daniel Barrientos, examinan las políticas activas de empleo, en concreto, tratan del papel de la formación en la empresa destinado a mejorar la empleabilidad de los jóvenes y la adecuación de su formación a los requerimientos de cualificaciones profesionales de las empresas.

Finalmente aprovechamos la ocasión para agradecer a todos los autores su contribución a este volumen del Anuario IET de Trabajo y Relaciones Laborales.

Bellaterra, a 10 de noviembre de 2017

Antonio Martín-Artiles

Director Institut d'Estudis del Treball.

Universitat Autònoma Barcelona. 